\title{
Pass-resistance Coupling Road Structure Research in Permafrost Region
}

\author{
Zhong Yongqiang \\ Transportation College, Huaiyin Institute of Technology, Huai'an 223003, China \\ email: zyqjlu@126.com
}

\begin{abstract}
Keywords: Permafrost region, Pass-resistance coupling road structure, Heat-resistant surface, Heat dissipation roadbed, Prevention countermeasures.

Abstract. In order to reduce the permafrost thaw disease of asphalt pavement caused by heat absorbing and conduction in permafrost regions, pass-resistance coupling structure is designed and its working principle is introduced. On the basis, heat resistance effect of pass-resistance coupling structure is analyzed by numerical analysis method. Thermal analysis results show that pavement structure of heat resistance coordinates with appropriate thickness of gravel road embankment can well prevent heat from incoming to permafrost soil in summer and can fully release heat in winter for the reason of thermal semiconductor effect of level gravel layer and chimney effect of incline gravel layer. Thus the total heat input can be significantly reduced. The melting depth and temperature field asymmetry are greatly reduced. So the occurrence probability of longitudinal cracks and other pavement diseases can be greatly reduced. It also has important theoretical and practical significance to the construction and maintenance of road construction in permafrost area in the future.
\end{abstract}

\section{Introduction}

As pavement structure construction and operation breaking down the original permafrost thermal equilibrium in permafrost region, heat total annual revenue of soil under the asphalt pavement is greater than the total expenditures. The heat into the roadbed stores and transfers to the depths. Cumulative heat leads to artificially limit deepening year by year and could easily cause embankment settlement, road surface waves, pavement longitudinal cracks and other diseases. Because of special climatic and geological conditions in permafrost region, road construction in the region has been regarded as a worldwide difficult problem [1].

From the 1960s to the late 1990s, in order to prevent the generation of road diseases in permafrost region, at least thirteen kinds of measures was explored in countries around the world. Pavement aspect mainly measures are light-colored pavement, solar heat-reflective coatings and seal coat of thermal resistance for asphalt pavement [2-4]. Passive measures of roadbed aspects are slope brushing white paint, building awning, EPS and XPS subgrade insulation material measures [5-7]. Initiative temperature control mainly measures are ventilation roadbed, thermal probe and gravel roadbed [8-11]. Among all roadbed measures, ventilation roadbed and thermal probe are high cost. Gravel roadbed is regarded as an effective and economical, active control methods.

Overall, research in permafrost regions at home and abroad is mostly focused on roadbed or pavement structure respectively. The existing roadbed and pavement measures have use effects, cost, structural safety or other application problems in different degree. It has not yet found the specialized study of subgrade and pavement working together to protection permafrost at home and abroad. Thaw in order to reduce a variety of road due to asphalt pavement absorbs heat conduction disease. Pass-resistance coupling road structure is put forward and researched from the view of heat transfer in this paper, which has broad application prospects in permafrost regions in the future.

\section{Definition and Working Principle of Pass-resistance Coupling Structure}

Pass-resistance coupling structure refers to a new kind of road structure which hinder or delay the heat input by adopting one or several ways of radiation, convection and conduction in warm season, 
however, beneficial to heat release of road structure system as a whole in cold season. Subgrade and pavement are cooperative work to reduce the permafrost melting depth. The working principle of pass-resistance coupling structure is shown in Figure 1 (a) (b).
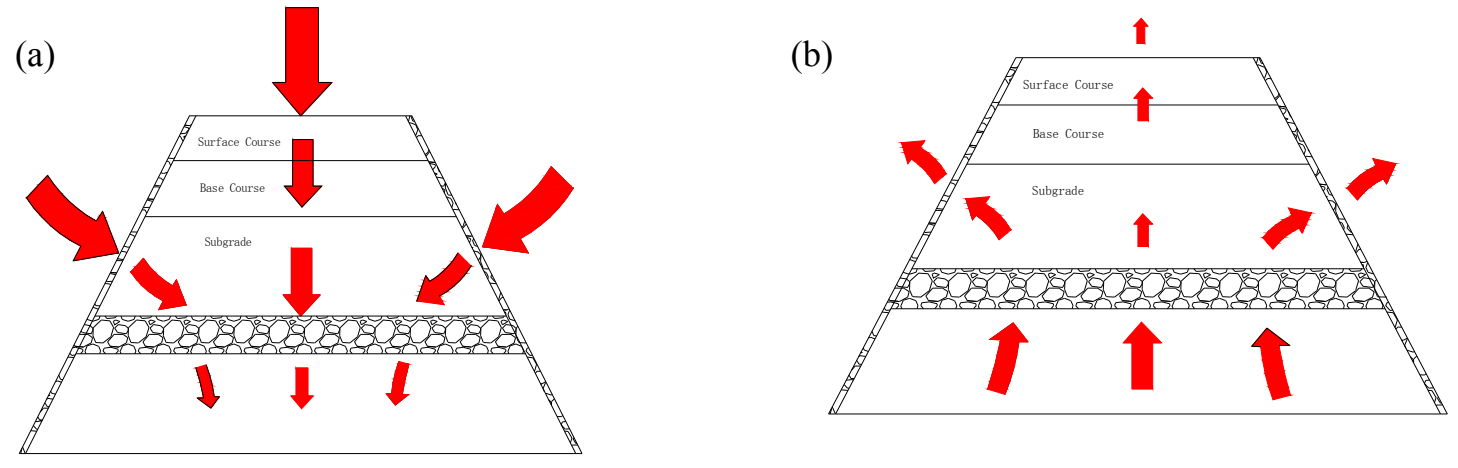

Fig.1 Working principle of pass-resistance coupling structure in warm and cold season (a) Heat flux analysis in warm season (b) heat flux analysis in cold season.

In warm season, the thermal resistant surface first hinder part of heat transfer downward. Inclined crushed rock layer (gravel slope) makes the cold air sink into lower part of rock massifs and resulted in the minimum temperature of lower part of rock massifs. Level gravel layer further reduced endothermic in warm season by the role of thermal semiconductor effect. Light warm air is in the upper and the heavier cold air is underneath. Because density stratification stability, there is no convection and heat exchange is mainly through conduction. Heat flux analysis is shown in Figure 1 (a).

In cold season, the heavier cold air is in the upper and Light warm air is underneath. Thermal semiconductor effect of level gravel layer strengthens the internal convection of much heat exchange to the surrounding. Although the pavement would hinder part of heat release, the gravel chimney effect of inclined crushed rock on both sides resulting in slope heat release. So that the winter cold of the frozen soil foundation stores more. Heat flux analysis is shown in Figure 1 (b). Results of the annual cycle is permafrost exothermic and temperature reduce. Especially with the growth of the using life, cumulative heat can be greatly reduced than ordinary roadbed. The upper limit of permafrost is raised and permafrost melting depth is reduced. The occurrence probability of pavement disease is reduced.

\section{Finite Element Analysis Model Foundation}

The overall direction of the Qinghai-Tibet Highway is north-south direction. Among them, top width of K2939+185 is $10 \mathrm{~m}$ and the total height of the embankment is $3 \mathrm{~m}$. The embankment slope is $1: 1.5$. The calculation range is $10 \mathrm{~m}$ transverse from the foot of roadbed on both sides and $20 \mathrm{~m}$ depth. Finite element model is shown in Figure 2. Unit type selects DC2D8 (of An 8-node quadratic heat transfer quadrilateral). The entire model is divided into 2925 units and 9012 nodes. Temperature boundary condition is imposed on pavement and two slope sides. U1 of the border of embankment is constrained and the bottom edge is fully constrained. Embankment Fill of K2939 +185 is sandy soil and pavement structure thickness is $52 \mathrm{~cm}$ which is shown in Figure 3 . Thermal parameters of Common road material are in Table 1. The solar radiation absorption rate is 0.8 and road emission rates is 0.93 . The absolute zero is $-273{ }^{\circ} \mathrm{C}$. The Stefan-to Boltzman constant is 2.041 $\times 10^{-4}\left(\mathrm{~J} / \mathrm{h} \cdot \mathrm{m}^{2} \cdot \mathrm{K}^{4}\right)[12]$. Temperature field calculation parameters of sub-grade layers are shown in Table 2 [13-15]. 


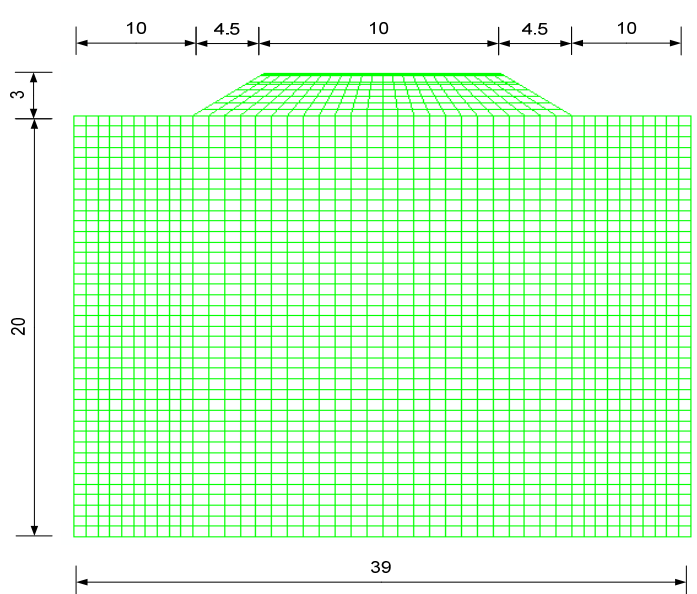

Fig.2 Temperature calculation model (m)

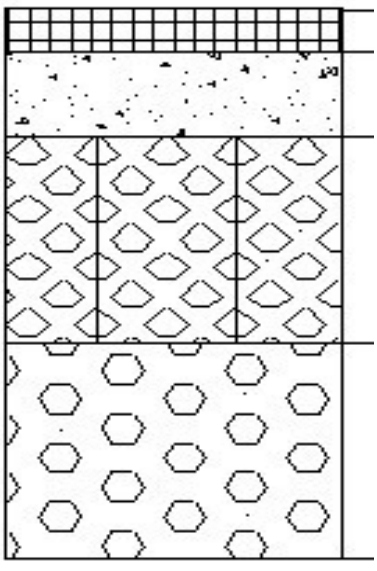

$4 \mathrm{~cm} \mathrm{AC}-13$

$8 \mathrm{~cm}$ Asphalt

stabilized crushed

$20 \mathrm{~cm}$ Cement stabilized gravel

$20 \mathrm{~cm}$ Gravel stone

Fig.3 Pavement structure of K $2939+185$ section

Tab.1 Thermal parameters of commonly used pavement material

\begin{tabular}{cccc}
\hline Material & $\begin{array}{c}\text { Thermal Conductivity k } \\
(\mathrm{W} / \mathrm{M} \cdot \mathrm{K})\end{array}$ & $\begin{array}{c}\text { Specific heat capacity } \\
\mathrm{C}(\mathrm{kJ} / \mathrm{kg} \cdot \mathrm{K})\end{array}$ & $\begin{array}{c}\text { Temperature } \\
\text { shrinkage coefficient } a \\
/{ }^{\circ} \mathrm{C}-\end{array}$ \\
\hline AC-13 & 1.15 & 1.67 & $2 \times 10^{-5}$ \\
AC-16 & 1.20 & 1.67 & $2 \times 10^{-5}$ \\
Asphalt stabilized crushed stone & 0.81 & 1.26 & $2 \times 10^{-5}$ \\
Cement stabilized gravel & 1.63 & 0.96 & $1 \times 10^{-5}$ \\
Gravel stone & 1.68 & 1.10 & $1 \times 10^{-5}$ \\
Graded broken stone & 0.90 & 2.00 & $1 \times 10^{-5}$ \\
\hline
\end{tabular}

Tab.2 Material parameters of sub-grade of the Qinghai-Tibet highway

\begin{tabular}{ccccc}
\hline Material & $\begin{array}{c}\text { Grand soil } \\
(2.48 \mathrm{~m} \text { thick })\end{array}$ & $\begin{array}{c}\text { Stone silty clay } \\
(7.2 \mathrm{~m} \text { thick })\end{array}$ & $\begin{array}{c}\text { Containing gravel } \\
\text { silty clay }(2.5 \mathrm{~m} \text { thick })\end{array}$ & $\begin{array}{c}\text { Strong weathered } \\
\text { mudstone }\end{array}$ \\
\hline $\begin{array}{c}\text { Specific heat of thawing soil } \\
(\mathrm{kJ} / \mathrm{kg} \cdot \mathrm{K})\end{array}$ & 0.79 & 1.44 & 0.84 & 0.84 \\
$\begin{array}{c}\text { Specific heat of frozen soil } \\
(\mathrm{kJ} / \mathrm{kg} \cdot \mathrm{K})\end{array}$ & 0.71 & 1.17 & 0.75 & 0.75 \\
$\begin{array}{c}\text { Thermal conductivity of thawing soil } \\
(\mathrm{W} / \mathrm{m} \cdot \mathrm{K})\end{array}$ & 1.92 & 0.95 & 0.87 & 1.47 \\
$\begin{array}{c}\text { Thermal conductivity of frozen soil } \\
(\mathrm{W} / \mathrm{m} \cdot \mathrm{K})\end{array}$ & 1.98 & 1.19 & 1.22 & 1.82 \\
\hline
\end{tabular}

Consider the impact of global warming, assume temperatures of the Qinghai-Tibet Plateau will increase by $2.6{ }^{\circ} \mathrm{C}$ in 50 years and initial annual average temperature $-4{ }^{\circ} \mathrm{C}$.According to the boundary layer theory, the asphalt pavement temperature increases $6.5^{\circ} \mathrm{C}$ and set boundary conditions as following [16-17].

Air temperature changes as the following formula:

$$
T_{a}=-3.5+12 \sin \left[\frac{2 \pi}{8760} t+\frac{\pi}{2}\right]+\frac{2.6 t}{438000}
$$

Natural surface temperature changes as the following formula:

$$
T_{n}=1.5+12 \sin \left[\frac{2 \pi}{8760} t+\frac{\pi}{2}\right]+\frac{2.6 t}{438000}
$$

Sunny slope temperature changes as the following formula:

$$
T_{s}=1.2+15 \sin \left[\frac{2 \pi}{8760} t+\frac{\pi}{2}\right]+\frac{2.6 t}{438000}
$$

Shady slope temperature changes as the following formula:

$$
T_{s^{\prime}}=0.8+15 \sin \left[\frac{2 \pi}{8760} t+\frac{\pi}{2}\right]+\frac{2.6 t}{438000}
$$

Asphalt pavement temperature changes as the following formula: 


$$
T_{p}=2.0+15 \sin \left[\frac{2 \pi}{8760} t+\frac{\pi}{2}\right]+\frac{2.6 t}{438000}
$$

\section{Working Effect Analysis of Pass-resistance Coupling Road Structure}

\subsection{Structural Composition of Pass-resistance Coupling Road Structure}

The proposed typical design of the pavement structure in spermafrost region are shown in Figure 4.Ventilation and radiating roadbed is made up of $1.5 \mathrm{~m}$ thick gravel whose particle size is $6-8 \mathrm{~cm}$.Cooling roadbed mainly uses two basic principles of Rayleigh Benard convection mechanism and the chimney effect. Rayleigh Benard (RB) convection and chimney effect is both buoyancy-driven natural convection [18]. Observational data and theoretical studies indicate that the gravel layer does play a role of cooling roadbed and stable subgrade .In the pavement structure, the thermal parameters of heat resistant surface material are determined by material thermal testing.

\subsection{Heat Resistant Surface Material Design and Thermal Parameters Test}

The aggregate grading design of ordinary AC-13 asphalt mixture is shown in Table 3 (total aggregate mass $1200 \mathrm{~g})$.

Tab.3 Aggregate grading design of ordinary AC-13 asphalt mixture

\begin{tabular}{lcccccccccc}
\hline Sieve size $/ \mathrm{mm}$ & 13.2 & 9.5 & 4.75 & 2.36 & 1.18 & 0.6 & 0.3 & 0.15 & 0.075 & $<0.075$ \\
\hline $\begin{array}{l}\text { Passing ratio } \\
\text { (by mass) } / \%\end{array}$ & 96 & 70 & 43 & 32 & 23 & 17 & 12 & 8 & 6 & 0 \\
\hline
\end{tabular}

Form Marshall specimens by using basalt aggregates and SBS modified asphalt. Take $4.5 \%, 4.8 \% 5.1 \%, 5.4 \%$ and 5.7\% five asphalt content to do Marshall test . Based on the test result and taking climate of permafrost zone into account, optimum oil-stone ratio is $5.5 \%$. In order to keep mechanical performance and compare easily, AC-13 aggregate gradation is not changed while filling ZS (stands for raw vermiculite) material. Based on screening result, the ZS material only substitute the aggregate each crosspiece below $2.36 \mathrm{~mm}$ by the same quality . Thermal conductivity and heat capacity test of asphalt concrete specimens of different ZS content $0,4 \%, 6 \%, 8 \%, 10 \%$ is done by Canadian TCI thermal analyzer (Figure 5). Test results are shown in Table 4 . The thermal conductivity of ZS content $10 \%$ drops the biggest $46.27 \%$. Compared to ordinary pavement, temperature reduction extent of $4 \mathrm{~cm}$ below the surface of heat resistant pavement can reach to maximum $2{ }^{\circ} \mathrm{C}$. The incoming heat from asphalt surface layer is significantly reduced in summer.

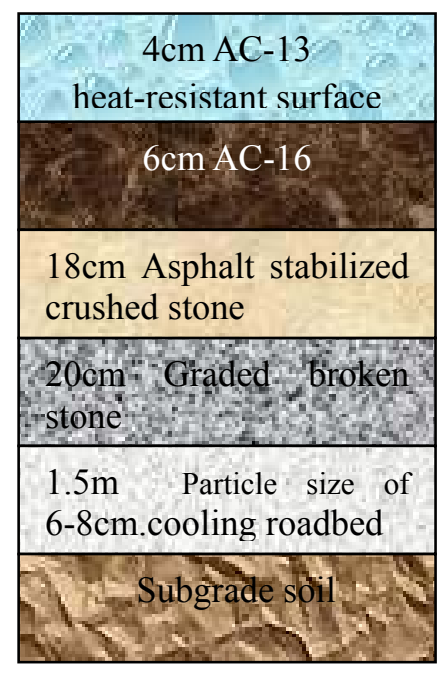

Fig. 4 Typical pass-resistance coupling pavement structure design

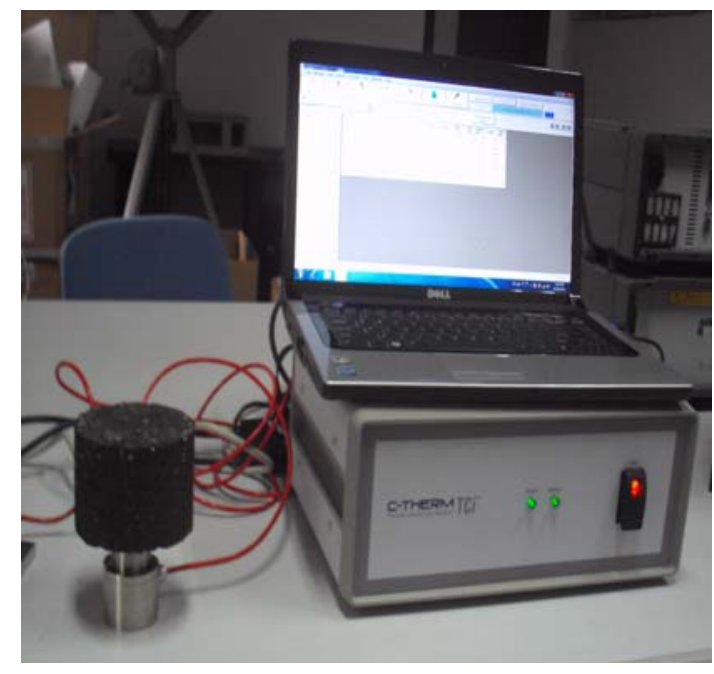

Fig.5 Thermal parameters determination of asphalt concrete specimens by TCI 
Tab.4 Thermal conductivity and heat capacity of different ZS content (ambient temperature of $27.8^{\circ} \mathrm{C}$ )

\begin{tabular}{ccc}
\hline ZS content $(\%)$ & Thermal conductivity $(\mathrm{W} / \mathrm{m} \cdot \mathrm{K})$ & Heat capacity $(\mathrm{J} / \mathrm{Kg} / \mathrm{K})$ \\
\hline 0 & 1.154 & 716.24 \\
4 & 0.891 & 691.68 \\
6 & 0.814 & 657.44 \\
8 & 0.724 & 633.62 \\
10 & 0.570 & 613.24 \\
\hline
\end{tabular}

\subsection{Comparative Analysis of Work Effectiveness of Pass-resistance Coupling Structure}

In order to show the effect of pass-resistance coupling structure, the temperature field calculation results of flexible base structure of typical pass-resistance coupling structure and K2939+185 sectional structure of the Qinghai-Tibet highway are selected to do contrast. Starting point of air temperature and road surface temperature fluctuations in sine curve is April 10. The highest point of temperature is on July 10. Temperature back to zero is on October 10. Temperature is the lowest point on January 10 and returns to the zero temperature on April 10 of the following year. The point $3 \mathrm{~m}$ and $5 \mathrm{~m}$ under the center of the road is selected as representative points to be analyzed. It can be seen from Figure 6 and Figure 7 that ground temperature of pass - resistance coupling structure is significantly reduced and the highest temperature was significantly delayed. The permafrost melting depth is significantly reduced. Compared to ordinary K2939 +185 structure, pass-resistance coupling structure has the following features:

(1) Temperature drop range is up to $2^{\circ} \mathrm{C}$ at road center away from the surface of $3 \mathrm{~m}$;

(2) The highest temperature phase lags about more than two months;

(3) The cumulative effect of heat is reduced. The maximum permafrost melting depth is reduced from $3.7 \mathrm{~m}$ to $2.5 \mathrm{~m}$ the lowered range up to $1.2 \mathrm{~m}$ The maximum drop percentage is $32.43 \%$.

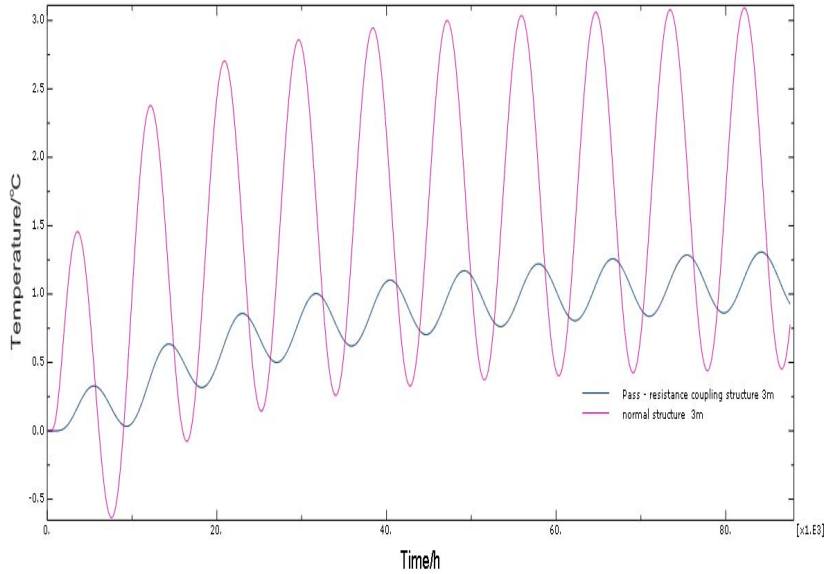

Fig.6 Temperature of $3 \mathrm{~m}$ away from surface of road center of two contrast structures for 10 years road center of two contrast structures for 10 years

\subsection{Temperature Field Analysis after Setting Gravel Slope on the Sunny Side}

Although the permafrost melting depth of pass - resistance coupling structure is significantly reduced, thaw deformation caused by permafrost phase change is reduced. However, the temperature field is also asymmetric and adding gravel slope can make temperature field symmetry. The sunny side sets $1.6 \mathrm{~m}$ wide gravel layer whose particle size is $6 \mathrm{~cm}$ to $8 \mathrm{~cm}$ to analyze its structure temperature field in the paper. Temperature field comparison $1 \mathrm{~m}$ under the shoulder is shown in Figure 8(a)(b) and Figure 9.After setting $1.6 \mathrm{~m}$ gravel slope on the sunny side, Temperature of $1 \mathrm{~m}$ under the shoulder on both sides is very close and the maximum temperature is between $3{ }^{\circ} \mathrm{C}$ to $4{ }^{\circ} \mathrm{C}$. Melting and refreezing is synchronization on both sides of pass - resistance 
coupling structure after setting gravel slope. After setting gravel slope, structure can better release heat in cold reason as shown in Figure 10.The permafrost melting depth is only $1 \mathrm{~m}$.
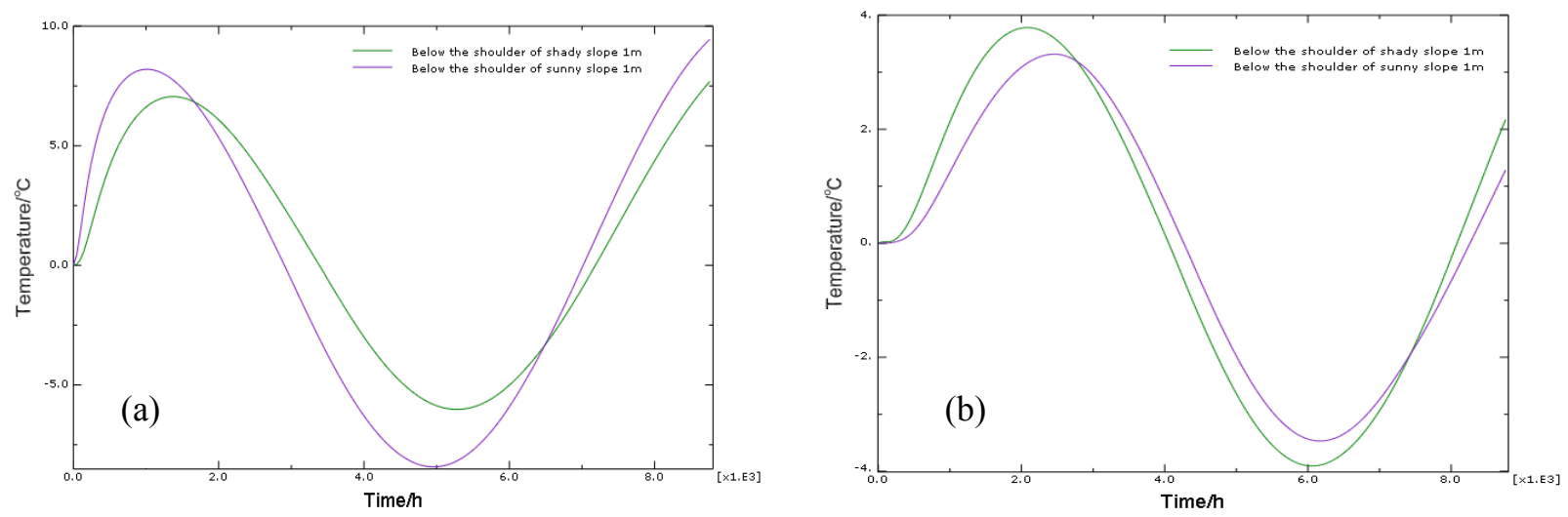

Fig. 8 Temperature field comparison of $1 \mathrm{~m}$ under the shoulder (a) before setting gravel slope (b) after setting gravel slope

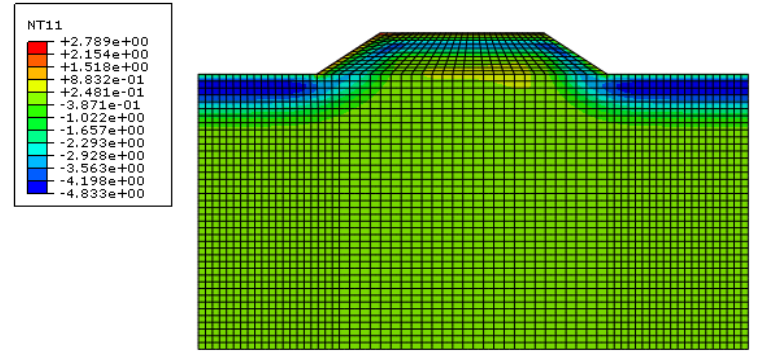

Fig.9 Temperature field of adding gravel slope in early April

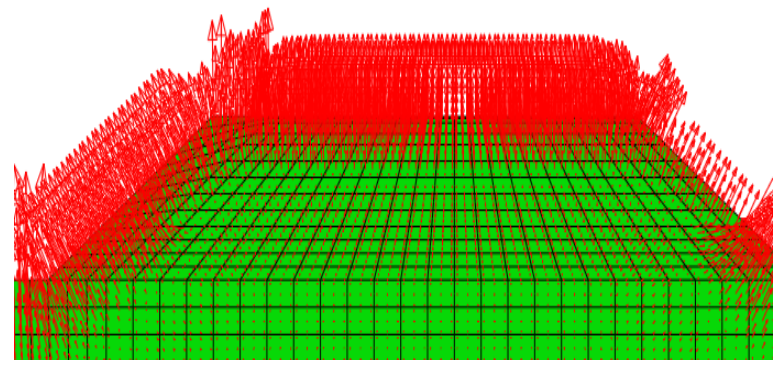

Fig.10 Exothermic vector field of adding gravel slope in cold season.

\section{Conclusions}

The following conclusions can be obtained through the research of pass - resistance coupling structure.

(1) The thermal conductivity of ZS content $10 \%$ drops the biggest $46.27 \%$.Compared to ordinary pavement, temperature reduction extent of $4 \mathrm{~cm}$ below the surface of heat resistant pavement can reach to maximum $2{ }^{\circ} \mathrm{C}$. The incoming heat from the asphalt surface layer is significantly reduced in summer. It will play positive role on protecting the permafrost over the years.

(2) Compared to ordinary structure, the temperature drop range of pass - resistance coupling structure is up to $2{ }^{\circ} \mathrm{C}$ at road center away from the surface of $3 \mathrm{~m}$. The highest temperature phase lags about more than two months. The cumulative effect of heat is reduced. The maximum permafrost melting depth is reduced from $3.7 \mathrm{~m}$ to $2.5 \mathrm{~m}$ the lowered range up to $1.2 \mathrm{~m}$ The maximum drop percentage is $32.43 \%$.

(3) Adding gravel slope can make temperature field symmetry. Melting and refreezing is synchronization on both sides of pass - resistance coupling structure after setting gravel slope. After setting gravel slope, structure can better release heat in cold season. The permafrost melting depth is only $1 \mathrm{~m}$.

\section{Acknowledgement}

In this paper, the research was sponsored by the Project supported by the Natural Science Foundation of the Jiangsu Higher Education Institutions of China(Grant No. 15KJB580002) , Huaian Science and Technology Development Project (Project No. HAGZ2014007) and of Jiangsu housing and Urban Construction Department Project (Project No.2014ZD33). 


\section{References}

[1] Wang S.J. Highway Construction Technology in the Permafrost Region of China [M]. Beijing:China Communication Press, 2008.

[2] Berg, R.L., D.C. Esch. Effect of color and texture on the surface temperature of asphalt concrete pavements, Proc. 4th International Conerence on Permafrost, 1983.

[3]Chen J., Sheng Y., Cheng, G.D. Discussion on protection measures of permafrost under the action of engineering from the point of earth surface energy balance equation in Qinghai -Tibet Plateau. Journal of Glaciology and Geocryology, 28(2),pp223-228, 2006.

[4] Feng D.C.,Yi J.Y. Study on mechanism and performance of tack and seal coat of thermal resistance for asphalt pavement. Journal of Highway and Transportation Research and Development,26(5),pp.1-5,2009.

[5] Yu, Q.H., Pan, X.C., Cheng, G.D., He, N.W. An experimental study on the cooling mechanism of a shading board in permafrost engineering. Cold Regions Science and Technology,53(3), pp.298-304, 2008.

[6]Xu J.F., Douglas J. Goering. Experimental validation of passive permafrost cooling systems. Cold Regions Science and Technology, 53(3),pp.283 -297, 2008.

[7] Sheng, Y., Zhang, J.M., Liu, Y.Z., Wu, J.M. Thermal regime in the embankment of Qinghai-Tibetan Highway in permafrost regions. Cold Regions Science and Technology,35(1), pp.35-44, 2002.

[8]Yu, Q.H., Niu, F.J., Pan, X.C., Bai, Y., Zhang, M.Y. Investigation of embankment with temperature-controlled ventilation along the Qinghai-Tibet railway. Cold Regions Science and Technology, 53(2),pp.193-199, 2008.

[9]Lai, Y.M., Guo, H.X., Dong, Y.H. Laboratory investigation on the cooling effect of the embankment with L-shaped thermosyphon and crushed-rock revetment in permafrost regions, 58(3), pp.143-150, 2009.

[10]Cheng, G.D., Lai, Y.M., Sun, Z.Z. The "thermal semi-conductor" effect of crushed rocks. Permafrost and Periglac. Process, 18(2),pp.151-160, 2007.

[11]Wu Q.B., Cheng H.B., Jiang G.L., et al. Cooling mechanism of block stone embankment in Qinghai-Tibet Railway. Science in China (Series E),50(3),pp.613 -620, 2007.

[12] Liao G.Y.,Huang X.M. ABAQUS finite element software in road engineering [M], Nanjing: Southeast University Press, 2008.

[13] Wang S.J.,Huang X.M.,Hou S.G. Numerical analyses of pavement deformation and stress in permafrost regions[J].Journal of Glaciology and Geocryology,28(2),pp.217-222,2006.(in Chinese)

[14 ]Ma B.,WANG B.G. Pavement base structures and materials in frozen soil regions [M]. Beijing:China Communication Press, 2007.

[15] Lai Y.M., Zhang M.Y., Li S.Y. Theory and Application of Cold Regions Engineering[M].Beijing:Science Press,2009.

[16] Chou Y.L. Study on effect of the thermal regime of roadbed slope on melting morphology in high-temperature permafrost region[D].Cold and Arid Regions Environmental and Engineering Research Institute,2006.

[17] Wang S.J., CHEN J.B. Nonlinear analysis for dimensional effects of temperature field of highway embankment in permafrost regions on Qinghai-Tibet plateau[J]. Chinese Journal of Geotechnical Engineering, 30(10),pp.1544-1549,2008. (in Chinese)

[18] Cheng, G.D., Zhang, J.M., Sheng, Y., et al. Principle of thermal insulation for permafrost protection[J]. Cold Regions Science and Technology, 40 (3),pp.71- 79, 2004. 